\title{
UNPRECEDENTED USE OF MEDICAL ABORTION CAN BE INJURIOUS TO HEALTH
}

Nidhi Mishra

1. Assistant Professor. Department of Obstetrics \& Gynaecology, Bundelkhand Medical College, Sagar, M.P.

\section{CORRESPONDING AUTHOR}

Dr. Nidhi Mishra,

Assistant professor Obs \& Gynae,

Bundelkhand Medical College,

Tili road, Sagar, M.P.470001, India.

E-mail: drnidhimishra@yahoomail.com

Ph: 00919302912075.

ABSTRACT: Objective - To study the complications caused by self-administered medical abortion pills sold over the counter without any medical supervision. MATERIAL AND METHOD - This study was conducted in Bundelkhand medical college and associated Tili hospital, Sagar, from 1st January 2012 to 31st December 2012. Patients who presented to the outpatient department with the history of consuming medical abortion pills without medical practitioner's advice were included in the study. RESULT: 12 women presented with severe bleeding with features of shock (B.P. $<90$ systolic) and had to undergo emergency evacuation. Five women had to be given blood transfusions. Out of 86 women 40 had to be subjected to surgical evacuation because of incomplete abortion (46.5\%). Two women were admitted in the emergency ward with ruptured tubal ectopic pregnancy and had to undergo emergency surgery. CONCLUSION: The use of medical abortion pills without proper prior consultation and guidance by a medical practitioner is extremely dangerous for women and can cause severe morbidity and life threatening complications.

KEYWORDS: Medical abortion, self- administered, mifepristone, incomplete abortion, complications

INTRODUCTION: In our country very few restrictions are present regarding the sale of medical abortion pills and hence they are freely available to each and every one. The use of these drugs without proper knowledge and without following the proper guidelines can cause a lot of morbidity amongst less aware and ill-informed women [1][2]. Thus, a wonderful medicine which can be a boon to women is transformed into a curse.

A medical abortion is a type of non-surgical abortion in which abortifacient pharmaceutical drugs are used to induce abortion. An oral preparation for medical abortion is commonly referred to as an abortion pill. Medical abortion became an alternative method of abortion with the availability of prostaglandin analogues in the early 1970s and the antiprogestogen mifepristone in the 1980s ${ }^{[3]}$.

The most common early first-trimester medical abortion regimens use mifepristone in combination with a prostaglandin analogue (misoprostol or gemeprost) up to 63 days of gestational age, methotrexate in combination with a prostaglandin analogue up to 49 days gestation, or a prostaglandin analogue alone ${ }^{[4]}$. Mifepristone-misoprostol combination regimens work faster and are more effective at later gestational ages than methotrexate-misoprostol 
combination regimens [4]. Mifepristone-misoprostol and methotrexate-misoprostol combination regimens are more effective than misoprostol alone [4].

Medical abortion regimens using mifepristone in combination with a prostaglandin analogue are the most common methods used to induce second-trimester abortions in Canada, most of Europe, China and India. Medical methods for first trimester abortion have been demonstrated to be both safe and effective. Regimens that combine mifepristone or methotrexate with a prostaglandin such as misoprostol are more efficacious than a prostaglandin alone ${ }^{[5]}$.

The medical approach avoids the use of anaesthetics; this and the possibility of using it as an outpatient procedure may offer an advantage in under-resourced settings. There is little, if any, difference between medical and surgical abortion in terms of safety and efficacy ${ }^{[5]}$.

With self-administration, sometimes life threatening conditions like ectopic pregnancy can be missed which can endanger the life of these women [6]. Our already anaemic female population can become more so by the irrational use of these pills [6]. Hence we need to reinstate guidelines and formulate new rules restricting the sale of these pills without medical practitioner's prescriptions ${ }^{[7]}$.

MATERIAL AND METHODS: This was a study conducted in Tili Hospital, Sagar, M.P., a tertiary level care hospital (an associated hospital of Bundelkhand Medical college, Sagar). Out of the total 9125 women attending OPD one of Tili hospital from $1^{\text {st }}$ January 2012 to $31^{\text {st }}$ December 2012, 86 women who presented with the history of self-administration of medical abortion pills purchased over the counter without consulting a medical practitioner were included in the study. The complications that occurred were recorded like anaemia, sepsis, incomplete abortion, heavy bleeding, shock, etc. and it was tried to ascertain the cause of such complications from the women's history and examination. The data obtained in this study was tabulated and analysed using the Chi-square test and the $\mathrm{Z}$ test with $\mathrm{p}$ value of 0.05 taken as significant.

RESULT: Out of the total 9125 women attending OPD one of Tili hospital from $1^{\text {st }}$ January 2012 to $31^{\text {st }}$ December 2012, 86 women $(0.94 \%)$ presented with the history of use of medical abortion pills purchased over the counter without consulting a medical practitioner.

Out of these 86 women, majority (46) belonged to the age group between 25 to 30 years and also majority (67) was multigravidas. 47 of these women belonged to rural areas and 39 belonged to the urban areas. 75 of these women had taken these medicines at an inappropriate gestational age ( $p$ 0.05)[7][8], that is, either before five weeks or after seven weeks of gestation (Table -1).None of these women had had an ultrasonography either to confirm the gestation age or to rule out ectopic pregnancy(p 0.1 $)^{[7][8]}$. In majority of these women (52) the duration of bleeding was more than two weeks(p 0.048)[7][8](Table-2). 12 women presented with severe bleeding with features of shock (B.P.<90systolic) and had to undergo emergency evacuation after resuscitative measures. Haemoglobin was $8 \mathrm{gm} \%$ to $9 \mathrm{gm} \%$ in 55 women and less than $8 \mathrm{gm} \%$ in 20 women (p0.05) ${ }^{[8]}$ (Table-3). Five women developed severe anaemia $(\mathrm{Hb} \%<$ $5 \mathrm{gms} / \mathrm{dl}$ ) and had to be given blood transfusions.

Out of these 86 women 40 had to be subjected to surgical evacuation because of incomplete abortion (46.5\%) (p0.02) ${ }^{[8]}($ Table-4). Two women were admitted in the emergency ward with ruptured tubal ectopic pregnancy and had to undergo emergency surgery. Out of the rest, 29 women had irregular bleeding and were managed with haemostatic tablets, antibiotics 
and antispasmodics and 15 women needed no intervention as the abortion was complete and there was no untoward complication. . Interestingly, out of the total 177 surgical evacuations performed in the family planning OT for incomplete abortions, 40 cases could be accounted for by unsupervised use of medical abortion pills.

DISCUSSION : In our scenario, where a large number of women are illiterate and unaware, unprecedented or unsupervised use of Medical abortion pills can be extremely dangerous for some women. Self-administration of these pills without proper knowledge and without following proper guidelines can cause serious morbidity in terms of anaemia and sepsis[8]. As seen in our study, it can sometimes be life threatening in case of incomplete abortion and undiagnosed ectopic pregnancies.

Hence it is imperative to create awareness about the proper usage of these pills amongst our women, especially rural women and create and provide proper guidelines to all health care providers as well as all those chemists who dispense these medicines [8]. It might as well be beneficial to restrict the sale of these medicines without a health care practitioner's prescription so that women do not use these medicines inappropriately and a lot of complications can be warded off.

ACKNOWLEDGEMENT: I am extremely grateful for the guidance and support provided by my seniors and colleagues, namely Dr Vrunda Joshi, Professor and head of the department, Dr Neelesh Dalal, Professor, Dr Jagriti Kiran Nagar, Assistant professor, Department of Obstetrics and Gynaecology, Bundelkhand medical college, Sagar, M.P.

\section{REFERENCES :}

1. Acharya R, Kalyanwala S.Knowledge, attitudes and practices of certified providers of medical abortion: evidence from Bihar and Maharashtra, India. Int J Gynaecol Obstet. 2012 Sep; 118Suppl 1:540-6.

2. Sri BS, Ravindran TK. Int J Gynaecol Obstet. Medical abortion: Understanding perspective of rural and marginalized women from rural South India. Int J Gynaecol Obstet. 2012 Sep;118Suppl 1:53-9.

3. Tamang A, Tamang J. Availability and acceptability of medical abortion in Nepal: health care provider's perspective. Reprod Health Matters. 2005 Nov;13(26): 110-9.

4. Kulier R, Gulmezoglu AM, Hofmeyr GJ, Cheng LN, Campana A. Medical methods for first trimester abortion. Cochrane Database Syst Rev. 2004;( 2)CD002855. Review. Update in: Cochrane Database Syst Rev. 2011;(11):CD002855.

5. Fielding SL, Edmunds E, Schaff EA. Having an abortion using mifepristone and home misoprostol: a qualitative analysis of women's experiences. Perspect Sex Reprod Health, 2002 Jan - feb; 34(1):34 - 40.

6. Harper C, Ellertson C, Winikoff B. Could American women use mifepristone-misoprostol pills safely with less medical supervision? Contraception. 2002 feb;(512):133-42.

7. Thoai D Ngo, Min Hae Park, Haleema Shakur, Caroline Free. Comparative effectiveness, safety and acceptability of medical abortion at home and in a clinic: a systematic review. Bull World Health Organ. 2011 May 1; 89(5): 360-370.

8. GrayWinikoff B, Ellertson C. Elul B, Sivin L. Acceptability and Feasibility of early pregnancy termination by mifepristone - misoprostol. Results of a large multicentre 
trial in the United States. Mifepristone clinical trials. Arch Fam Med. 1998 Jul - Aug; $7(4): 360-6$.

Table -1 Gestational age at the time of ingestion of the pills

\begin{tabular}{|c|c|c|c|c|}
\hline S no. & $\begin{array}{c}\text { Gestational age in } \\
\text { weeks }\end{array}$ & Number of women & Percentage & P value \\
\hline 1. & $<5 \mathrm{wks}$ & 23 & $26.7 \%$ & 0.05 \\
\hline 2. & $5-7 \mathrm{wks}$ & 11 & $12.8 \%$ & 0.005 \\
\hline 3. & $>7 \mathrm{wks}$ & 52 & $60.5 \%$ & 0.05 \\
\hline
\end{tabular}

Table -2 Duration of bleeding

\begin{tabular}{|c|c|c|c|c|}
\hline S no. & Duration in weeks & Number of women & Percentage & P value \\
\hline 1. & $1 \mathrm{wks}$ & 10 & $11.6 \%$ & 0.001 \\
\hline 2. & $1-2 \mathrm{wks}$ & 24 & $27.9 \%$ & 0.005 \\
\hline 3. & $>2 \mathrm{wks}$ & 52 & $60.5 \%$ & 0.048 \\
\hline
\end{tabular}

Table - 3 Haemoglobin level at the time of presentation

\begin{tabular}{|c|c|c|c|c|}
\hline S no. & Haemoglobin in gms/dl & Number of women & Percentage & P value \\
\hline 1. & $>9 \mathrm{gms} / \mathrm{dl}$ & 11 & $12.8 \%$ & 0.001 \\
\hline 2. & $9-8 \mathrm{gms} / \mathrm{dl}$ & 55 & $63.9 \%$ & 0.048 \\
\hline 3. & $<8 \mathrm{gms} / \mathrm{dl}$ & 20 & $23.2 \%$ & 0.05 \\
\hline
\end{tabular}

Table -4 Outcome

\begin{tabular}{|c|c|c|c|c|}
\hline S no. & Intervention done & Number of women & Percentage & P value \\
\hline 1. & $\begin{array}{c}\text { No intervention } \\
\text { needed }\end{array}$ & 15 & $17.5 \%$ & 0.001 \\
\hline 2. & Surgical evacuation & 40 & $46.5 \%$ & 0.02 \\
\hline 3. & Laparotomy & 2 & $2.3 \%$ & 0.01 \\
\hline 4. & Medical treatment & 29 & $33.7 \%$ & 0.001 \\
\hline
\end{tabular}

